\title{
Liver Diseases in the Elderly: An Update
}

\author{
Annarosa Floreani \\ Department of Surgical and Gastroenterological Sciences, University of Padova, Padova, Italy
}

\section{Key Words}

Liver diseases in elderly $\cdot$ Non-alcoholic fatty liver disease • Hepatitis $C$ virus infection - Alcoholic liver disease .

Hepatocellular carcinoma $\cdot$ Liver transplantation

\begin{abstract}
Although there are no liver diseases specific to advanced age, the clinical course and management of liver diseases in the elderly may differ in several aspects from those of younger adults. During the last decade an explosion of new knowledge in liver disease has provoked increasing enthusiasm among hepatologists. On the other hand, the development of new emerging conditions (e.g. non-alcoholic steatohepatitis) and novel therapeutic approaches has made it increasingly difficult to validate and assimilate information to be applied in clinical practice. Some liver diseases in the elderly need to be revisited, particularly non-alcoholic fatty liver disease, chronic hepatitis $C$, alcoholic liver disease, and hepatocellular carcinoma. Moreover, some therapeutic approaches, especially antiviral therapy and liver transplantation, should be discussed also in selected groups of elderly patients.

Copyright $\odot 2007$ S. Karger AG, Basel
\end{abstract}

\section{Introduction}

The specific subject of chronic liver disease in the elderly has generally received little attention from hepatologists, probably for several reasons. First of all, there are no specifically age-related liver diseases. Secondly, some of the liver diseases that can develop in old age, particularly primary biliary cirrhosis and autoimmune hepatitis, do not represent a different diagnostic tool in the elderly and can easily be treated with standard therapy. Moreover, autoimmune liver disease carries a good prognosis in the elderly, and very few patients have clinically aggressive conditions. Even when we consider chronic liver disease in the very elderly ( $>80$ years old), cirrhosis is the main risk factor affecting prognosis [1]. In dealing with elderly people, however, it is important to consider the increase in the number of deaths unrelated to the liver, especially pneumonia, when liver disease gradually deteriorates [1].

Hepatitis B virus (HBV) infection is declining in many countries. Infected elderly people often develop a subclinical or oligosymptomatic hepatitis with a low rate of HBV clearance, possibly due to their impaired immunological status. Chronic hepatitis and/or cirrhosis are generally inactive and progress slowly. However, it is undeniable that in recent years there has been an increasing interest in distinguishing between old and young people as regards clinical liver disease and its management. In fact, one of the most important problems lies in the increasing number of elderly patients with chronic hepatitis $\mathrm{C}$ infection. Epidemiological figures suggest that elderly people form a cohort whose infection was acquired many years earlier. Another problem is the recent acquisition of metabolic conditions specifically affecting old age (diabetes, dyslipidemia) as important factors correlated to chronic liver disease. Finally, it is important to bear in mind the

\section{KARGER}

Fax +4161306 1234

E-Mail karger@karger.ch

www.karger.com (c) 2007 S. Karger AG, Basel

0257-2753/07/0252-0138\$23.50/0

Accessible online at:

www.karger.com/ddi
Prof. Annarosa Floreani

Division of Gastroenterology

Via Giustiniani, 2, IT-35128 Padova (Italy)

Tel. +39049821 2894, Fax +390498760820

E-Mail annarosa.floreani@unipd.it 
Table 1. Interferon monotherapy in the elderly

\begin{tabular}{llllll}
\hline Group & $>65$ years & $<65$ years & $\begin{array}{l}\text { Response } \\
\text { (end of treatment) }\end{array}$ & p & $\begin{array}{l}\text { Side } \\
\text { effects }\end{array}$ \\
\hline Bresci, 1993 [14] & 22 & 21 & 62 vs. $57 \%$ & NS & similar \\
Van Thiel, 1995 [15] & 25 & 25 & 48 vs. $41 \%$ & NS & similar \\
Horiike, 1995 [16] & $19(>60)$ & $52(<60)$ & SR $=26$ vs. 33\% & NS & similar \\
\hline
\end{tabular}

$\mathrm{SR}=$ Sustained response. increasing incidence of hepatocellular carcinoma (HCC) in old age, as a complication of end-stage liver disease. This chapter focuses on a few specific aspects of parenchymal liver disease that have recently been revisited in the elderly.

\section{Non-Alcoholic Fatty Liver Disease}

Non-alcoholic fatty liver disease (NAFLD) is a clinicopathological spectrum of liver abnormalities ranging from steatosis to non-alcoholic steatohepatitis (NASH). Its prevalence varies depending on the diagnostic methods used, but about $25 \%$ of the general population in the USA is presumably affected. An Italian population survey based on ultrasound found steatosis in $16.4 \%$ of the general population, in $46.4 \%$ of heavy drinkers, in $75.8 \%$ of obese subjects, and in $94.5 \%$ of obese drinkers [2]. $\mathrm{NASH}$ is mainly related to metabolic disorders including obesity, insulin resistance, hyperlipidemia, nutritional disorders, inherited lipoprotein metabolism disorders, drug use and toxin ingestion. While prospective studies on the natural history of NASH are still lacking, approximately $10-15 \%$ of patients will progress to advanced fibrosis and cirrhosis [3]. It is now clear that a large proportion of cases with cryptogenic cirrhosis represent the end-stage liver disease of NASH [4]. In this light, cases of cryptogenic cirrhosis in old age may conceivably be due to metabolic risk factors developing in adult life. A combination of age $>45$ years with obesity, diabetes mellitus, and AST/ALT $>1$ has been identified as a predictor of liver fibrosis [5]. Liver failure is the main cause of morbidity and mortality in NASH-associated cirrhosis. The prognosis is either comparable with, or less severe than for hepatitis $\mathrm{C}$ virus (HCV) cirrhosis, except that $\mathrm{HCC}$ appears to be less common [6].

\section{Hepatitis C Virus Infection}

This is the most important clinical form in the elderly. Besides the epidemiological figures that indicate an increasing prevalence of anti-HCV with age [7], at the onset of infection or the diagnosis of chronic hepatitis, old age is clearly associated with more severe histological damage and the presence of cirrhosis [8]. Risk factors for elderly people acquiring HCV differ considerably from those of the younger generations. In fact, epidemiological studies suggest an epidemic of HCV infection during the Second World War and in the early post-war years. The epidemiological factors included blood transfusions, but the main culprits were non-disposable syringes [9]. In young people, on the other hand, HCV infection is mainly due to risk behavior, including tattooing, piercing, and sharing contaminated needles among intravenous drug users.

The clinical spectrum of cases with active replication ranges from no biochemical or clinical signs of liver disease right up to decompensated cirrhosis, sometimes with superimposed HCC [10].

\section{Treatment Strategies for Hepatitis $C$}

Asymptomatic carriers have mild histological changes and rarely develop advanced disease [11, 12]. The natural history of this group of patients appears to progress slowly, if at all. Experts differ on whether to biopsy and treat these patients [13]. In our opinion, antiviral treatment is not to be recommended for such elderly patients, whereas follow-up is, with liver function tests and $\alpha$-fetoprotein every 6 months and liver ultrasound annually.

Elderly patients with chronic hepatitis $\mathrm{C}$ are generally considered poor candidates for antiviral treatment due to the predictably low rate of response and the high rate of adverse effects. Only three studies with interferon (IFN) as monotherapy have been published so far (table 1). Two controlled studies $[14,15]$ included a small sample of subjects ( 21 and 25 , respectively) $>65$ years old, with an aver- 
Table 2. Side effects of IFN and ribavirin therapy

\begin{tabular}{cll}
\hline Frequency & IFN- $\alpha$ & Ribavirin \\
\hline$>30-50 \%$ & Fatigue, fever, arthralgia, headache & Hemolysis, dyspepsia \\
\hline $1-30 \%$ & Mild depression & Anemia \\
& Thrombocytopenia & Pruritus \\
& Leukocytopenia & Cough \\
& Anorexia & Rash \\
& Severe depression & Severe angina \\
& Diabetes & Gout \\
& Autoimmune diseases (thyroid dysfunction) & Myocardial infarction \\
& Neuropathy & \\
\hline
\end{tabular}

age age of 68.8 years [14] and an age range of $65-81$ years [15]. In both studies, the response at the end of the treatment did not differ significantly in the elderly group by comparison with younger patients, and the percentage of side effects was similar in the two groups. Any viremia was not investigated in these studies and the rate of sustained response is not reported. Horiike et al. [16] treated 19 patients $>60$ years old (average age 62.5 years) with IFN and compared the results with 52 younger adult patients (average age 44.1 years): the percentage of sustained response did not differ significantly in the two groups (26 vs. $33 \%$, respectively).

Older patients may be at risk of neurological side effects of IFN, e.g. confusion, lethargy, cognitive changes and depression, especially if they have a history of neurological and/or psychiatric disorders [17]. Selected individuals $<70$ years old might thus be candidates for antiviral therapy. The National Institute of Health Consensus Conference on hepatitis C defined IFN + ribavirin combination therapy as the new standard treatment for chronic hepatitis C [13]. More recently, the addition of a polyethylene glycol molecule to IFN has improved its pharmacokinetics, requiring its administration only once a week. Multiple side effects are common, and occasionally severe. Predosing with antipyretics, paying attention to hydration and ensuring adequate rest periods are also important. As elderly patients have a higher chance of side effects than younger patients, accurate patient monitoring is also necessary. The most common side effects are listed in table 2.

A number of cost-benefit analyses have evaluated parameters for predicting response to combination therapy. In general, old age, genotype 1, high viral load and a high degree of histological fibrosis are associated with a low sustained response rate [18]. There are no reports available on controlled trials with IFN + ribavirin in elderly patients, but we have recently enrolled 33 naive patients with a mean age $\pm \mathrm{SD}$ of $70.2 \pm 1.2$ years to receive pegylated IFN- $\alpha 2 \mathrm{~b}$ at a dose of $1.5 \mathrm{mg} / \mathrm{kg}$ weekly plus ribavirin for 6 (genotype 2 or 3 ) or 12 (genotype 1 or 4 ) months. Tolerance and efficacy were compared to those observed in a 1:2 adult group matched for sex, genotype, viral load, and grading/staging parameters [19]. The results of this study indicate that elderly patients have a higher likelihood of side effects and significantly lower rate of virological response at the end of treatment and 6 months afterward than younger adults. Cost-benefit analysis shows that only selected patients aged 65 and older should be treated.

There is a general consensus that adult patients who have failed to respond, or have responded only temporarily to IFN alone, should be offered a combination of IFN + ribavirin, unless they have major contraindications to such therapy. There are no reports on retreatment with antiviral therapy in the elderly, or rather the number of older patients involved in any such studies has been too small to assess the tolerability of this combination in older people. In our opinion, retreatment is not to be recommended in elderly patients because of the high risk of side effects.

There is only one published study using IFN + amantadine in patients $>65$ years of age whose prior treatment with IFN had failed to eradicate HCV infection [20]. In this trial, 165 patients were randomized into three groups and treated for 12 months: group A received amantadine $100 \mathrm{mg}$ twice a day; group B received IFN- $\alpha 6 \mathrm{MU}$ every other day for 3 months followed by $3 \mathrm{MU}$, and group C was given the same dose of IFN- $\alpha$ as group B plus amantadine $200 \mathrm{mg} /$ day. The percentage of sustained response was $16.6 \%$ in group A, $23 \%$ in group B, and $25 \%$ in group C. Although the tolerability of this combination, this trial does not appear to substantially improve the sustained 
response rate in elderly patients who have failed to become clear of HCV infection after IFN monotherapy.

Amantadine alone is not effective in patients $>70$ years old with contraindications for antiviral therapy [21].

\section{Alcoholic Liver Disease}

Alcohol consumption is common in old age. In a study on community-dwelling people ranging from 60 to 92 years of age, $62 \%$ of the subjects were drinkers, and heavy drinking was reported in $13 \%$ of men and $2 \%$ of women [22]. However, the criteria commonly used to define alcohol abuse and dependence may be difficult to apply to older people, particularly when they have retired or have few social contacts [23]. Half of the elderly patients who develop cirrhosis die within a year of its diagnosis [24]. Alcohol abuse has been mentioned in many studies as contributing to the progression of $\mathrm{HCV}$ related liver disease. In a study including 800 patients with HCV infection, heavy drinking ( $>50 \mathrm{~g}$ of ethanol a day) was associated with an increase in mean fibrosis $(\mathrm{p}=0.01)$ [25]. However, on multivariate analysis in a cohort of patients with hepatitis $\mathrm{C}$, none of the alcohol intake categories (light, moderate and heavy) correlated with the presence of steatosis in either genotype 3 and other genotypes [26]. The effects of alcohol may also be compounded in elderly patients by age-related pharmacological changes involving interactions between alcohol and medication.

Alcohol withdrawal in elderly subjects should be supervised by a health care professional [27].

\section{Hepatocellular Carcinoma}

HCC is the most common complication of liver cirrhosis affecting elderly people. The rate of HCC increases with age in cirrhotic patients [28]. A number of studies conducted in different groups of patients have established that, due to its long natural history, HCV infection contributes to the greater risk of HCC in the elderly. A recent prospective study carried out on a homogeneous cohort of 312 patients with initially compensated cirrhosis of viral etiology in the last 15 years has identified HCC as the most frequent and life-threatening complication, particularly in HCV-positive cases [29]. HCC often preceded the appearance of ascites and was the cause of death in $70.7 \%$ of the patients [29]. A relatively low carcinogenesis rate has been observed in extremely elderly patients, how- ever (nearly $5 \%$ per year in the HCV-related liver cirrhosis group) [1].

HCV and HBV coinfection is a condition particularly prone to malignant transformation [9]. Another emerging condition that contributes to the development of HCC in old age is NAFLD. Although prospective studies on this condition are lacking, several reports have identified cryptogenic cirrhosis as the end stage of liver disease due to metabolic factors underlying NAFLD-related cirrhosis. Moreover, the hypothesis that obesity and diabetes mellitus are important risk factors for cryptogenic chronic liver disease in patients with HCC is supported by the analysis of surgically-treated patients [30]: in a series of 18 patients who underwent liver resection for HCC developing on cryptogenic cirrhosis, 12 patients were $>65$ years of age. These observations have prompted the increasing interest in surveillance programs for cirrhotic patients, aiming to detect any HCC development as early as possible.

The treatment of HCC in elderly subjects deserves some considerations. Hepatic resection can be safely done in cirrhotic HCC patients $>70$ years of age, but the prognosis for these patients is less favorable than for patients $<70$ years, even when curative resection is achieved [31]. Liver transplantation is an exceptional measure for elderly patients, due to many current data concerning the management of HCC. Many transplant centers restrict the waiting list for HCC for patients $<65$ years; moreover, the problem of the increasingly long waiting lists obviously restricts the life expectancy for patients with malignancies. Radiofrequency ablation, alcohol injection and transcatheter arterial chemoembolization are non-surgical treatment modalities for HCC that are currently performed in elderly patients.

\section{Liver Transplantation}

Liver transplantation is considered an acceptable treatment for fulminant liver damage. According to the European Liver Transplant Registry, the proportion of adult liver recipients older than 60 years increased from $9 \%$ in 1990 to more than $16 \%$ by 1999 . Moreover, more than $10.7 \%$ of recipients of a liver allograft in the USA in 2000 were $>65$ years old. Randall et al. [32] examined data from the Organ Procurement and Transplant Network for the last 10 years to determine whether it is justifiable to perform transplantation in older patients. For liver transplant recipients $>65$ years old, the annual death rate per 1,000 patients per year at risk rose from 49 in 1991 to 
185 in 2000. The total number of patients increased from 382 in 1991 to 3,181 in 2000, for a rate of 183.8 in 1991 and 85.5 in 2000 . However, the survival rate, as reported in the European Liver Transplant Registry for more than 3,000 liver recipients $>60$ years of age, was significantly shorter than for a group of 11,762 recipients aged 45-60 years $(\mathrm{p}<0.001)$. The shorter survival in elderly patients is due to several comorbidity factors, such as cardiopulmonary disease and advanced kidney dysfunction [32]. The recipient's age is particularly important as a predictive factor for survival among patients with hepatitis $\mathrm{C}$ [33]. On the other hand, the outcome of liver transplantation with a graft from a donor $>65$ years of age into an $\mathrm{HCV}$-positive recipient shows a worse outcome than with organs from younger donors [34]. Generally speaking, several studies report a decline in the survival rates of patients who receive organs from donors older than 45.5 or 60 years even in etiologies other than hepatitis C. In a recently published study, patient survival is lower when the donor is $>30$ years old, and hepatic graft survival is reduced at a cut-off donor age $>25$ years [35]. Obviously, organ donation cannot be limited for reasons of age because the number of donations would be insufficient. However, there are many other aspects of this topic warrant discussion and evaluation. One important point to make, for example, is that organs from older donors should be given to older recipients. Another important area of debate is whether it is ethical to consider healthy family members as donors for the elderly population.

\section{References}

$>1$ Hoshida Y, Ikeda K, Kobayashi M, Suzuki Y, Tsubota A, Saitoh S, Arase Y, Kobayashi M, Murashima N, Chayama K, Kumada H: Chronic liver disease in the extremely elderly of 80 years or more: clinical characteristics, prognosis and patient survival analysis. J Hepatol 1999;31:860-866.

-2 Bellentani S, Saccoccio G, Masutti F, Crocè LS, Brandi G, Sasso F, Cristianini G, et al: Prevalence and risk factors for hepatic steatosis in Northern Italy. Ann Intern Med 2000;132:112-117.

$>3$ Angulo P: Nonalcoholic fatty liver disease. N Engl J Med 2002;346:1221-1231.

$\checkmark 4$ Neuschwander-Tetri BA, Caldwell SH: Nonalcoholic steatohepatitis: summary of an AASLD single topic conference. Hepatology 2003;37:1202-1219.

$\checkmark 5$ Angulo P, Keach JC, Batts KP, Lindor KD: Independent predictors of liver fibrosis in patients with nonalcoholic steatohepatitis. Hepatology 1999;30:1356-1362.

6 Hui JM, Kench JG, Chitturi S, Sud A, Farrell GC, Byth K, Hall P, Khan M, George J: Longterm outcomes of cirrhosis in non alcoholic steatohepatitis compared with hepatitis C. Hepatology 2003;38:420-427.

$>7$ Poynard T, Yen MF, Ratziu V, Lai CL: Viral hepatitis C. Lancet 2003;362:2095-2100.

$>8$ Pagliaro L, D’Amico G, Puleo A: Meta-analysis as a source of evidence in gastroenterology: a critical approach. Ital J Gastroenterol Hepatol 1999;31:723-742.

$>9$ Chiaramonte M, Stroffolini T, Vian A, Stazi MA, Floreani A, Lorenzoni U, Lobello S, Farinati F, Naccarato R: Rate of incidence of hepatocellular carcinoma in patients with compensated viral cirrhosis. Cancer 1999; 85:2132-2137.
10 Marcus E-L, Tur-Kaspa R: Chronic hepatitis $\mathrm{C}$ virus infection in older adults. Clin Infect Dis 41:1606-1612, 2005.

11 Puoti C, Castellacci R, Montagnose F, Zaltron S, Stornaiuolo G, Bergami N, Bellis L, Precone D, Corvisieri P, Puoti M, Minola E, Gaeta GB: Histological and virological features and follow-up of hepatitis $\mathrm{C}$ virus carriers with normal aminotransferase levels: the Italian prospective study of the asymptomatic C carriers (ISACC). J Hepatol 2002; 37:117-123.

12 Hoofnagle JH: Management of hepatitis C: current and future perspectives. J Hepatol 1999;31(suppl 1):264-268.

$13 \mathrm{NIH}$ Consensus Statement on Management of Hepatitis C: 2002. HIH Consens State Sci Statements 2002;19:1-46.

14 Bresci G, Del Corso L, Romanelli AM, et al: The use of recombinant interferon-alfa-2b in elderly patients with anti-HCV-positive chronic active hepatitis. J Am Geriatr Soc 1993;41:857-862.

15 Van Thiel DH, Fridlander L, Caraceni P, et al: Treatment of hepatitis $C$ virus in elderly persons with interferon- $\alpha$. J Gerontol 1995; 50:M330-M333.

16 Horiike N, Masumoto T, Nakanishi K, et al: Interferon therapy for patients more than 60 years of age with chronic hepatitis C. J Gastroenterol Hepatol 1995;10:246-249.

17 Marcus E-L, Tur-Kaspa R: Viral hepatitis in older adults. J Am Geriatr Soc 1997;45:755763.

18 Gao B, Hong F, Radeva S: Host factors and failure of interferon- $\alpha$ treatment of hepatitis C virus. Hepatology 2004;39:880-890.
19 Floreani A, Minola E, Carderi I, Ferrara F, Rosa Rizzotto E, Baldo V: Are elderly patients poor candidates for pegylated interferon plus ribavirin in the treatment of chronic hepatitis C? J Am Geriatr Dis 2006; 54:549-550.

20 Bacosi M, Russo F, D’Innocenzo S, Santolamazza M, Migliorasi L, Ursitti A, De Angelis A, Patrizi F, Ricci GL: Amantadine and interferon in the combined treatment of hepatitis $\mathrm{C}$ virus in elderly patients. Hepatol Res 2002;22:231-239.

21 Torre F, Campo N, Giusto R, Ansaldi F, Icardi GC, Picciotto A: Antiviral activity of amantadine in elderly patients with chronic hepatitis C. Gerontology 2001;47:330-333.

22 Mirand AL, Welte JW: Alcohol consumption among the elderly in a general population from Erie County, New York. Am J Public Health 1996;86:978-984.

23 Adams WL, Cox NS: Epidemiology of problem drinking among elderly people. Int J Addict 1995;30:1693-1716.

24 Smith JW: Medical manifestations of alcoholism in the elderly. Int J Addict 1995;30: 1749-1798.

25 Monto A, Patel K, Bostrom A, Pianko S, Pockros P, McHutchison JG, Wright TL: Risks of a range of alcohol intake on hepatitis-C-related fibrosis. Hepatology 2004;39: 826-834.

26 Fabris P, Floreani A, Carlotto A, Giordani MT, Baldo V, Stecca C, Marchiorio L, Tramarin A, Bertin T, Negro F, deLalla F: Alcohol is an important co-factor for both steatosis and fibrosis in Northern Italian patients with chronic hepatitis C. J Hepatol 41:644651, 2004.

27 Rigler SK: Alcoholism in the elderly. Am Fam Physicians 2000;61:1710-1716. 
28 Ikeda K, Saitoh S, Suzuki Y, Kobayashi M, Tsubota A, Koida I, Arase Y, Fukuda M, Chayama K, Murashima N, Kumada H: Disease progression and hepatocellular carcinogenesis in patients with chronic viral hepatitis: a prospective observation of 2,215 patients. J Hepatol 1998;28:930-938.

29 Benvegnù L, Gios M, Alberti A: Natural history of compensated viral cirrhosis: a prospective study on the incidence and hierarchy of major complications. Gut 2004;53: 744-749.
30 Regimbeau JM, Colombat M, Mognol P, Durand F, Abdalla E, Degott C, Degos F, Farges $\mathrm{O}$, Belghiti J: Obesity and diabetes as a risk factor for hepatocellular carcinoma. Liver Transpl 2004;2(suppl 1):S69-S73.

31 Lui WY, Chau GY, Wu CW, King KL: Surgical resection of hepatocellular carcinoma in elderly cirrhotic patients. Hepatogastroenterology 1999;46:640-645.

32 Randall HR, Cao S, deVera ME: Transplantation in elderly patient. Arch Surg 2003;138: 1089-1092.

-33 Zetterman RK, Belle SH, Hoofnagle JH, Lawlor S, Wei Y, Everhart J, Wiesner RH, Lake JR: Age and liver transplantation: a report on the liver Transplantation Database. Transplantation 1998;66:500-506.
34 Baccarani U, Adani GL, Toniutto P, Sainz M, Lorenzin D, Viale PL, Ramacciato G, Risaliti A, Bresadola F: Liver transplantation from old donors into $\mathrm{HCV}$ and non-HCV recipients. Transpl Proc 2004;36:527-528.

35 Fernandez-Merino FJ, Nuno-Garza J, Lopez-Hervas P, Lopez-Buenadicha A, Quijano-Collazo Y, Vicente-Lopez E: Donor age a risk factor for patient survival in the liver transplant. Transpl Proc 2003;35:17951797. 